\title{
Initial economic appraisal of nuclear district heating in France
}

\author{
Frédéric Jasserand* and Jean-Guy Devezeaux de Lavergne \\ I-tésé, CEA, DEN (Nuclear Energy Division), University Paris-Saclay, CEA Saclay, 91191 Gif-Sur-Yvette cedex, France
}

Received: 11 December 2015 / Received in final form: 20 April 2016 / Accepted: 29 June 2016

\begin{abstract}
Although cogeneration with nuclear power has been proving its feasibility for many years and in many parts of the world, the French nuclear fleet does not use this technique. Nevertheless, current developments within the energy context may offer new opportunities to review the use of nuclear cogeneration. This paper focuses on the use of cogeneration for district heating and its possible development perspectives within the French energy transition. After recapping some common assumptions about nuclear cogeneration, we will describe the techno-economic model that we built to evaluate the characteristics of introducing cogeneration into an already operating power plant. The second step consists in applying the above-described model to a usecase describing the heating of the Parisian area, which represents the largest target for this study. The last step presents the results of a simplified model derived from the first step. Summarizing the model's main input data in a few pertinent parameters gives an initial picture of the potential for developing nuclear district heating in France.
\end{abstract}

\section{Introduction}

The year 2015 is important as it gave France the opportunity to assert its ambitions in terms of environmental policy. During the summer, the French National Assembly ratified the Energy Transition bill (loi relative à la transition énergétique pour la croissance verte, LTECV) which sets out the government's targets for improving energy performance and reducing greenhouse gas emissions [1]. And at the end of the year, the COP21 conference took place in Paris, welcoming a record number of stakeholders who agreed on a new international agreement to maintain global warming below $2{ }^{\circ} \mathrm{C}[2]$.

Cogeneration - a process whereby electricity and heat are produced simultaneously from the same fuel-is particularly well suited to these governmental ambitions as it reduces the primary energy consumption for the same final uses.

Thus, cogeneration was retained as one of the solutions which could lead to a factor- 4 reduction in greenhouse gas emissions by 2050 according to ANCRE (the French National Alliance for Energy Research Coordination which combines the main organizations involved in this field) [3].

\footnotetext{
* e-mail: frederic.jasserand@cea.fr
}

This scenario suggests that if many thermal production plants in France today run in cogeneration mode while producing electricity at the same time, the "reverse" use of nuclear reactors to produce heat as a coproduct could open up a vast potential of tens of $\mathrm{TWh}_{\mathrm{th}}$ which is currently put to no use.

Nuclear cogeneration is used for district heating in several European countries [4], but its specificities limit its use to small projects where either the delivered heat or the transport distance between the production site and the consumption site is small. The precedence of these projects also questions the feasibility of such operations in the current economic conditions.

The objective of this paper is to assess the potential of using nuclear combined heat and power (CHP) for district heating $(\mathrm{DH})$ in France. After summarizing the main principles of cogeneration used for DH in Section 2, we will discuss the building of a techno-economic model adapted to the study of such projects in Section 3. The two last sections will then use this model to assess the cogeneration solution for Paris (Sect. 4). Section 5 will extend the analysis by applying this model to other nuclear power plants (NPPs).

It must be stressed that the schemes proposed in this paper take place in a mutating world, particularly in terms of the market rules. Thus, the emergence of nuclear cogeneration, which is a long-term process, cannot be assessed within the current situation alone. Uncertainties remain great even if a voluntary policy can reduce them, thus opening new opportunities. 


\section{Nuclear cogeneration for DH}

\subsection{Main concepts of cogeneration}

All the currently operating French NPPs are pressurised water reactors (PWRs). They were designed purely to generate electricity, and their efficiency varies from $32 \%$ (900 MWe reactor series) to $35 \%$ (N4 $1450 \mathrm{MWe}$ reactor series).

Thermal energy which is not converted into electricity is mainly dispersed into the environment by the tertiary circuit as low-temperature water $\left(<40^{\circ} \mathrm{C}\right)$ or steam. However, this energy cannot be used in these forms for domestic or industrial use, and it would be necessary to modify the circuits and their exchanges to be able to extract usable energy. This would involve a certain decrease in the amount of electricity generated, which would have to be accepted as the compromise for this solution.

To describe this usability more precisely, it is better to consider the exergy, defined as: $E=H-T_{0} \cdot S$ (where $E$ : enthalpy, $T_{0}$ : outside temperature and $S$ : entropy).

In the case of thermal non-equilibrium, exergy is proportional to the difference between the temperature at which heat is produced, $T$, and the environmental temperature $T_{0}$. As energy is proportional to temperature, the ratio between exergy and energy can then be expressed as [5]:

$$
\frac{E}{Q}=\frac{T-T_{0}}{T} \text { or } E=Q\left(\frac{T-T_{0}}{T}\right) .
$$

This is the Carnot efficiency formula, which links the maximal mechanical energy that can be extracted, the used heat, and the cold and hot sink temperatures.

If part of the heat from the secondary system is used for heating, then the mechanical efficiency (electricity) will decrease and the associated loss of production is a cost (opportunity cost) in the economic calculation of the heat. This cost is linked to the electricity loss and the selling prices of heat and electricity. In the case of a PWR, the ratio between the electricity lost and the extracted thermal energy is around $1 / 5$ for water at $120^{\circ} \mathrm{C}$.

This means that the use of cogeneration is then economically viable only if the sales of heating are greater than the corresponding loss of electricity.

Because in France the demand for electricity and heating occurs at approximately the same time, this cost can be high when the price of electricity reaches its maximum in winter in Western Europe.

In addition to production costs, the cost of distribution often hinders the development of DH. Even if, for historical reasons, heating in the tertiary sector and living areas is mainly delivered by electricity [6], the installation costs of heating distribution networks limit their extension to areas with sufficient population density and already using a compatible heating process (central or collective heating). In the current economic conditions, the threshold is around $5-9 \mathrm{MWh}_{\text {th }}$ per linear meter per year [7].

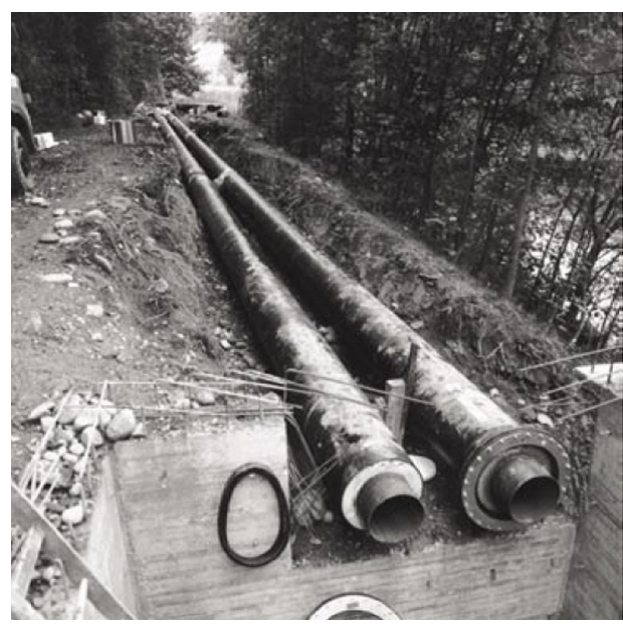

Fig. 1. Building the main heat transport line [9].

However, such investment yields are sustainable in the long-term as the operating lifetime of the distribution network represents several decades: the best example in France is the Parisian network for which the first pipes were installed in 1927 [8] (Fig. 1).

\subsection{Specifics of nuclear cogeneration}

The heat required for DH typically varies between 110 and $160^{\circ} \mathrm{C}$. From a techno-economic point of view, this choice of temperature is a critical parameter as it governs the competition between the production of electricity and heat. Depending on the selected temperature, heat is extracted from the secondary loop before the medium pressure (MP) turbine and/or before the low-pressure (LP) turbine. For a DH application, it has already been stated that the goal of $110^{\circ} \mathrm{C}$ stands as a good compromise [10]. This temperature results partly from the advantage of liquid water as the heat transfer fluid and the choice of avoiding high pressures.

Figure 2 shows a simplified diagram of the complete $\mathrm{DH}$ system, with the following abbreviations: SG, steam generator; HP/LP, high-/low-pressure turbines; P, pump; $\mathrm{C}$, condensor; CS, cold source; HE, heat exchanger; MTL, main transport line; DN, distribution network.

NPPs are sited far away from densely populated areas. Though these distances are suitable for the transport of electricity, delivering large amounts of heat through heavy isolated pipes is an entirely different matter and a new issue, even if nuclear-based $\mathrm{DH}$ projects were studied in France in the 1970s around Paris and Grenoble [11].

Associated costs may be controlled by above-ground pipe installations, but for legal and environmental reasons, the most preferred solution is to bury them in trenches or tunnels. The corresponding investment (from a few to more than ten $\mathrm{M} € / \mathrm{km}$ ) can become prohibitive for the project.

Moreover, nuclear reactors can produce large amounts of heat compared with conventional thermal facilities $\left(\mathrm{GTPP},{ }^{1} \mathrm{MWIP}^{2}{ }^{2}\right.$ etc.) and its unavailability (e.g. during

\footnotetext{
${ }^{1}$ Gas thermal power plant.

${ }^{2}$ Municipal waste incineration plant.
} 


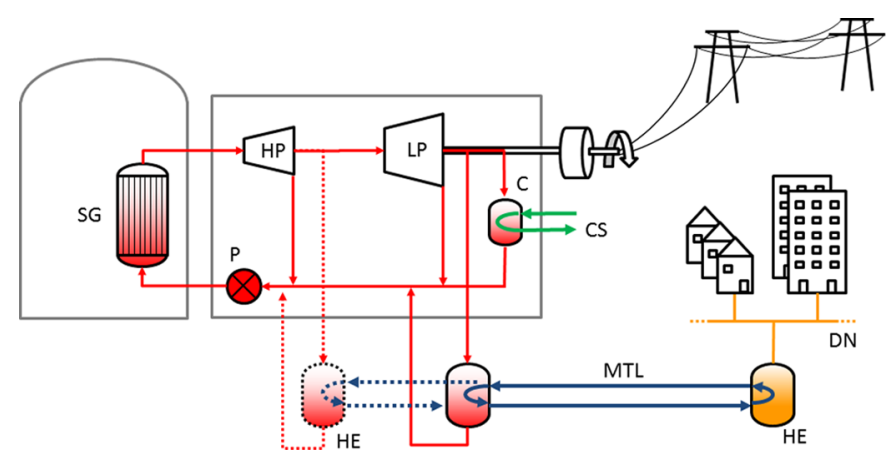

Fig. 2. Diagram of nuclear cogeneration for DH (personal work).

fuel reloading operations) is more difficult to manage. This issue is similar to that of the necessary correspondence between the power produced by a nuclear reactor and the critical size of the electric grid to which it is connected.

No more than a few $100 \mathrm{MW}_{\text {th }}$ have ever been produced in the past. This means that the corresponding infrastructures, including the main transport line (MTL) pipes, do not exist at all. It may prove challenging to design them (due to pressure and thermal losses) and manufacture them at a controlled price. However, there is consensus on the fact that the modifications to be made to NPPs in the case of cogeneration represent no specific technical difficulties [12].

The social acceptability of the technique is also problematic. Even if the public opinion on nuclear power is still relatively good several years after the Fukushima disaster [13], we have no French sociological studies focusing on the development of this technique. It is possible that a series of technical measures, e.g. redundancy of barriers between the reactor and the domestic loop (4 between the 5 loops for the Beznau circuit), could boost acceptation, but this question still remains open.

From a safety viewpoint, the loss of this secondary cold sink must be assessed, e.g. in the case of an incident affecting the MTL. The study of this kind of event implies a review of the command system of the reactor.

In other countries, different conditions have allowed significant developments in DH. These systems share similar characteristics, including some or all of the following: - They are deployed in countries where the weather has long been the main drive behind the development of $\mathrm{DH}$ networks, i.e. mainly in Eastern Europe: Russia, Ukraine, Bulgaria, Czech Republic, etc.

- There are relatively short distances between the NPP and the DH system: $<30 \mathrm{~km}$ (with 2 exceptions in Russia: Kola: $64 \mathrm{~km}$ and Novovoronezh: $50 \mathrm{~km}$ ).

- The heat extracted is limited to a few tens of $\mathrm{MW}_{\mathrm{th}}$ : $\leq 60 \mathrm{MW}_{\mathrm{th}}$ for half of the projects, from 100 to $240 \mathrm{MW}_{\mathrm{th}}$ for the others.

Some larger projects have already been studied but remain to be deployed, such as the Loviisa-Helsinki project [14].

Ultimately, deployment of nuclear cogeneration in France for the purposes of DH will be a gradual process. We need to examine its use from a new perspective, to take account of the Energy Transition Act, the increasing costs of fossil fuels over the long-term and the technological advancements in transportation techniques.

\subsection{DH in France}

Compared with countries in Central and Eastern Europe, France uses few heating networks, and the fraction of the population connecting to them was only $7.4 \%$ in 2013 (compared with 10-30\% in central Europe) [15]. This figure conceals the strong heterogeneity behind $\mathrm{DH}$, as the Parisian region (Île-de-France) uses more than the half the total heat, 13.6 $\mathrm{TWh}_{\mathrm{th}}$ (with 5.5 for Paris alone), while the second region (Rhône-Alpes) is far behind with $2.9 \mathrm{TWh}_{\mathrm{th}}$ and covering three main cities. Other networks are mainly deployed in the north-east quarter of France and are limited to a few hundreds of $\mathrm{GWh}_{\text {th }}$ per year [16].

The fact that there is no inventory of the heating networks in France is a clear indication that there is currently no national policy around the use of such facilities. Yet local and regional initiatives are becoming more frequent which aim to encourage their development within the framework of the energy transition.

For the Ile-de-France region alone, where the bestdeveloped infrastructures are located, the growing potential of the heating networks is still important as it was recently assessed to be around a factor of 2 and estimated to reach $28 \mathrm{TWh}_{\mathrm{th}}$ in 2030 [7]. This doubling would result from a threefold increase in the number of connected residences and the counter-effect of an overall improvement in their energy performance (the Energy Transition Act draft will promote renovation works and new buildings will use stricter standards).

\subsection{Relevance of nuclear DH for the French energy transition}

As discussed earlier, ANCRE has put forward various potential scenarios for the evolving energy sector in France [3]. In its "diversified vectors" scenario (DIV), heating networks and nuclear cogeneration play an important role in reducing primary energy consumption in the domestic and commercial sectors. The DIV scenario assumes an approximate heat production of $240 \mathrm{TWh}$ by 2050, generated using "low carbon" technologies, with an equal split between renewable energies and nuclear cogeneration.

The Energy Transition Act sets a target to reduce the share of nuclear energy in electricity generation to $50 \%$ between now and 2025, compared with the current level of $75 \%$. With the specific aim of diversifying energy sources, there is thus a significant potential to use reactors for cogeneration, combining reactor availability with the added advantage of diversification into heat production. This approach would be consistent with an extension of reactor lifetime by 10 or even 20 years. Such an extension, which is frequently implemented in other countries [17], offers certain economic benefit since the investments associated with these plants have already been written off and the amount of work required to upgrade facilities is considerably less than that required to build a new plant. 
As the French fleet of nuclear reactors is very homogeneous (the 58 NPPs are built from only 4 different standardised plant series), the use of cogeneration could be simplified by pooling part of the technical studies and regulatory procedures.

\section{Techno-economic model}

\subsection{Main objective}

The aim of this article is to assess the potential of developing nuclear cogeneration for $\mathrm{DH}$ from existing NPPs in France.

A step in this study is to first develop a techno-economic model to provide a flexible tool that can describe any cogeneration project so as to assess its economic indicators. This model will then be applied to the French sites which seem to be the most relevant for DH.

The relevance of the model relies on the description of the project costs. They have to be adapted to each project under investigation in order to assess the economic conditions in which the project could be developed.

Note also that the model is adapted to the deployment of cogeneration within existing reactors. A very important task will be to examine this issue for new reactors, considering that, in this case, projects would offer a better overall design, no disruption associated with upgrading a unit in service and a longer planned service life.

\subsection{Model description}

All the costs for setting up the project have been sorted into three categories:

- "Design": the expenses which must be paid before the beginning of the building phase, such as the engineering and market studies, the regulation process, etc.

- "Investment": the expenses of building the infrastructures before the beginning of the operating phase, such as the modifications to the secondary loop of the plant, the purchase of the pipes for the MTL and their burying, the connection with the distribution network, etc.

- "Operations": the expenses relative to operation during the technical lifetime of the project (such as salaries, maintenance, pumps alimentation, etc.).

Depending on the project, another cost item includes the provision of a "back-up" system (e.g., a gas thermal power plant), capable of taking over in the event of reactor unavailability. An element of flexibility is required when considering this issue, depending, for example, on whether such methods already exist (substitution of most of this energy by nuclear cogeneration and maintenance of the production capacity for a back-up function), or, for example, on whether equipping several units on a single site would make it possible to limit the risk of a disruption in supply. Finally, it should also be considered that the planning of reactor refuelling outages, preferably in summer, favours the use of reactors for heating.

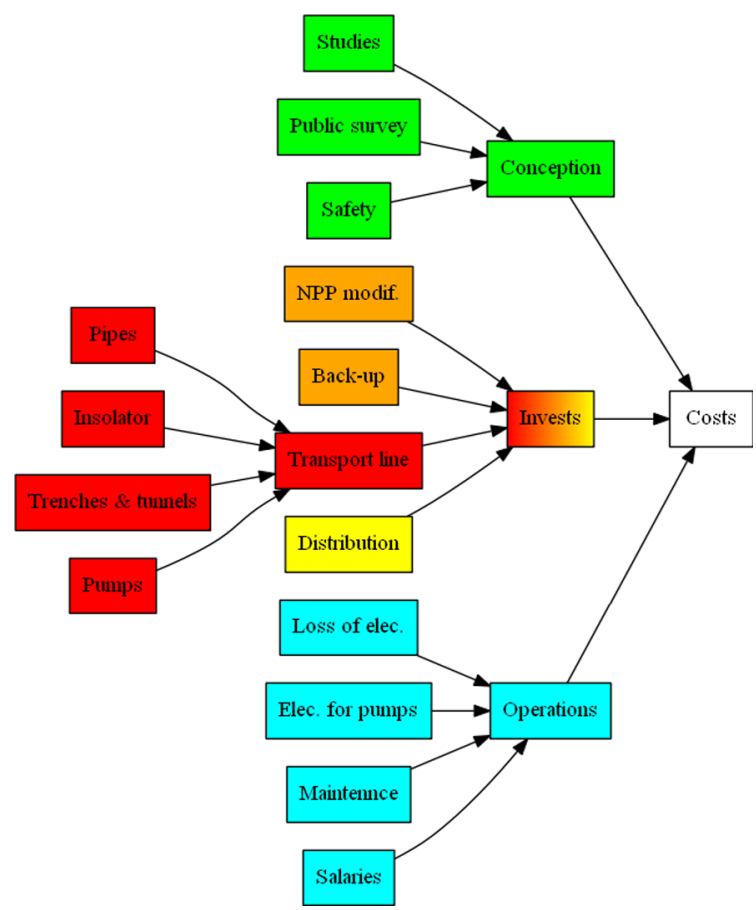

Fig. 3. Cost breakdown structure.

The main costs are represented in Figure 3 and fully described in the following paragraphs. This figure introduces the colour code which will be used later during the analysis of their relative contributions.

Design: Next to the technical studies, the largest contributions to this category are related to regulations. The first one is the safety analysis of the project by the nuclear regulatory authority and the equivalent validations from the administrative structures (city, department, region, etc.). The second one is the public enquiry required by French law for any new or modified project of importance; it consists in informing the public on the nature of the project, by meetings, debates, etc.

Both costs are difficult to assess as they are deeply related to the scope of the project, but some penalising assumptions show that these costs often remain small compared with the other categories.

Investment: They include two main items: extraction of the heat in the NPP to warm the heat transfer fluid, and building the MTL and its connection to the distribution network.

As mentioned earlier, developing the link up to the heating network is potentially the most significant cost item as it involves the purchase of large cast iron pipes with sufficient insulation to limit heat losses, potentially over long distances (typically several dozens of miles). Since the fluid being transported is superheated water, it is also necessary to install pumping stations along the route of the pipeline to ensure sufficient pressure at all points on the network. Finally, pipes are likely to be buried in trenches, which limit installation costs, or in tunnels in urban or suburban areas. From an economic viewpoint, trenches are the most cost-effective choice, but in the case of a major 
project, the dimensions of the pipes may limit their use in practice (for pipes greater than $1 \mathrm{~m}$ in diameter excluding the insulating material, the need to install two pipes - a "hot" supply pipe and a "cold" return pipe-may require excavation of more than $4 \mathrm{~m} \times 3 \mathrm{~m}$, or $12 \mathrm{~m}^{3}$, per linear meter of pipeline). Note also that there are concentric pipe systems which avoid the need for 2 pipes, but which also require large diameters (considerably greater than $1 \mathrm{~m}$ in practice).

For this study, we assumed that the distribution network already exists, so the only cost which must be assessed is that associated with the transport lines. This can be done by installing heat exchangers in dispatched substations.

To supply heat to an existing network also has the advantage of limiting investment in terms of back-up power since the thermal plants are already in place. Their amortisation and operation for several hundred hours per year nonetheless have to be taken into account because they will not be used as frequently as initially expected when designed. As these costs are much smaller in this study, they were finally disregarded.

Operation: The recurrent costs and revenue associated with the operating phase include not only the sale of heat but also the lower electricity output.

Expenses also include the salaries of all personnel mobilised in the power plant and the transport network, as well as the associated maintenance costs.

Finally, an economic assessment must be carried out looking a decade ahead or more. Over this time scale, the effect of the mechanisms designed to increase the cost of using fossil fuels (carbon tax, quotas market, etc.) can be taken into account for cases where nuclear cogeneration replaces a GHG-emitting process (gas or oil-fired heating systems or MWIP).

Other cost items: The financial charges (duties, taxes, insurances) are not evaluated here in the framework of a prospective study. This is because they are considered to be similar in the different assumptions studied. Interim costs are, however, included in the evaluations. The discount rate used is a low "public" rate, consistent with the rates applied when evaluating the long-term projects envisaged within the scope of the Energy Transition Act: $3 \%$ annual (real rate). This rate can, in particular, include the associated measures put in place by the government to support projects to develop nuclear district heating by cogeneration (subsidised loans for example).

\subsection{Technical parameters}

The main parameters characterising the projects studied are the amount of heat produced and the transport distance between the production site and the distribution network.

The duration of the demand for heat on the distribution site used is $t=3000 \mathrm{hrs} /$ year (corresponding to 3 months at full power and 3 months at half power).

Having defined (by extrapolating to the connection date) the timeline for supplying the required heat, it is possible to size the maximum thermal power $P$ (MWth) to be extracted from the NPP. This power is an outcome of a dynamic optimisation involving an uncertain future

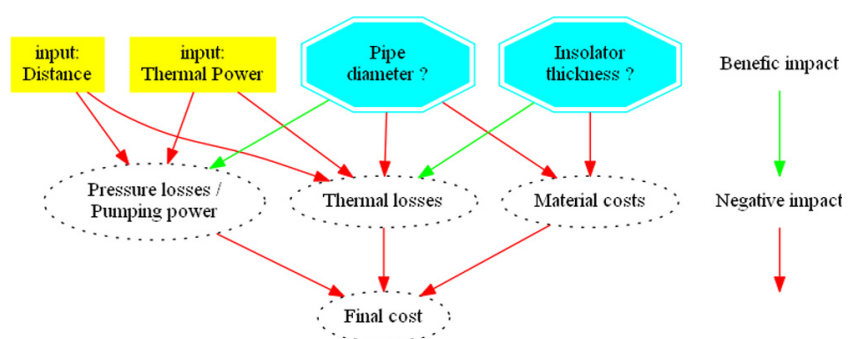

Fig. 4. Simplified chart of the main interactions between the critical variables of the system.

since it includes expectations about the development of the heating network, the price of electricity, the cost of heat generated by fossil fuels, the price of carbon emissions, etc.

Coupled with power, the transport distance $D(\mathrm{~km})$ determines in particular the needs in terms of pumping (the pressure of the superheated fluid must be maintained between two limit values) and pipe insulation (to limit thermal losses).

Energy and thermal losses, however, require knowledge of the diameter $\oslash(\mathrm{mm})$ of the pipes transporting the heat transfer fluid. This diameter is determined by iteration, whereby the different interactions between the variables modelled can actually have opposite effects on different variables, making it difficult to calculate the optimum solution for this system simply. More specifically:

- a large pipe diameter minimises energy losses and, thus, pumping power;

- a large pipe diameter increases the cost of materials (quantity of steel and volume of insulation) and installation (volume of earth excavated for trenches and tunnels), increases thermal losses (which means pipelines need thicker insulation), and increases the volume of fluid (Fig. 4).

Irrespective of the power extracted from the plant, the heat transfer fluid used here is water superheated to $110^{\circ} \mathrm{C}$, at a pressure in the order of $10-20$ bar. It is assumed that the interface with the distribution network is adjusted so that the return temperature is $60^{\circ} \mathrm{C}$.

The transport line comprises 2 cast iron pipes (one for supply and one for return) lagged with polyurethane insulation typically used for this type of application [18].

\subsection{Economic assessment}

The calculations associated with the service life of the project include a discount rate varying from $3 \%$ (consistent with high levels of state funding) to $5 \%$. A rate suitable for a private investor would be more in the order of $8 \%$ but the sums and risks involved impose de facto state support, thus justifying consideration of a lower rate. In addition, the present period of time offers very low interest rate, which lead to a decrease in the weighted average capital cost of private firms. In the end, a rate of a real $5 \%$ (net of inflation) appears to be sound.

In winter when heat is mainly consumed, the price of electricity is currently a maximum of $€ 80 / \mathrm{MWh}_{\mathrm{e}}$ on the spot market (peak price of December 2013) and less than 
$€ 50 / \mathrm{MWh}_{\mathrm{e}}$ on the futures market [19]. For our calculations, we are assuming a moderate, yet continuous rise in electricity prices, consistent with extensive research on the transition trajectories, such as that conducted by ANCRE [3]. Two assumptions are considered: a "favourable" price for cogeneration of $€ 60 / \mathrm{MWh}_{\mathrm{e}}$ and a second more prudent price of $€ 70 / \mathrm{MWh}_{\mathrm{e}}$.

Heat must be generated at a cost such that it can be sold in near-market conditions. In 2014, the average price in France was $€ 70 / \mathrm{MWh}_{\mathrm{th}}$, split between a fixed component of $35 \%$ (subscription) and a $65 \%$ variable component linked to consumption [16].

In reality, a significant disparity was observed in the Paris area between certain networks selling heat at less than $€ 50 / \mathrm{MWh}_{\mathrm{th}}$ and others, even in the inner suburbs, who were charging more than $€ 80 / \mathrm{MWh}_{\text {th }}$. The average price, controlled by the CPCU in Paris, ${ }^{3}$ is approximately $€ 60 / \mathrm{MWh}_{\text {th }}[20]$.

We have used an initial value based on this amount for our analysis. Supposing that the fixed component of the heat price is primarily associated with maintenance of the distribution network, the variable component representing the economic objective is thus $€ 39 / \mathrm{MWh}_{\text {th }}$.

On the other hand, since the price of "fossil" heat is expected to rise with the fixed limits on GHG emissions, a second value of $€ 54 / \mathrm{MWh}_{\text {th }}$ will also be considered. In both cases, we assume that these values are fixed over time.

The following economic parameters are evaluated: amount of investment (discounted and overnight CapEx), operating expenses $(\mathrm{OpEx})$ and their evolution throughout the life of the project (cash flows).

This information allows us to evaluate the net present value (NPV) for the project and the payout time (POT).

All of this expenditure is also represented in the form of a levelised cost of heat $(\mathrm{LCOH})$ which can be compared to the actual cost of generating the heat.

Because of the numerous uncertainties related to the input data, some analyses have been carried out using relative rather than absolute costs.

\section{Use-case Nogent/Paris}

\subsection{Main parameters}

The Nogent-sur-Seine plant has two 1300 MW PWRs commissioned in 1987 and 1988, respectively. They recorded load factors (Kp) of $83 \%$ and $80 \%$ in 2014 [21].

The Nogent site is the closest to Paris, located $95 \mathrm{~km}$ from Notre-Dame as the crow flies or approximately $D=90 \mathrm{~km}$ from Créteil following the main roads.

In order to optimise the costs of building the transport lines, we have split this distance into two separate sections. The first section, located in the relatively "rural" area ( $80 \mathrm{~km}$ from the plant to the town of Brie-Comte-Robert), comprises the MTLs which can be laid in trenches. Once into the more "urban" area, the route of the pipeline

\footnotetext{
${ }^{3}$ The "Compagnie Parisienne de Chauffage Urbain" is a local public company owned by Engie and the City of Paris.
}

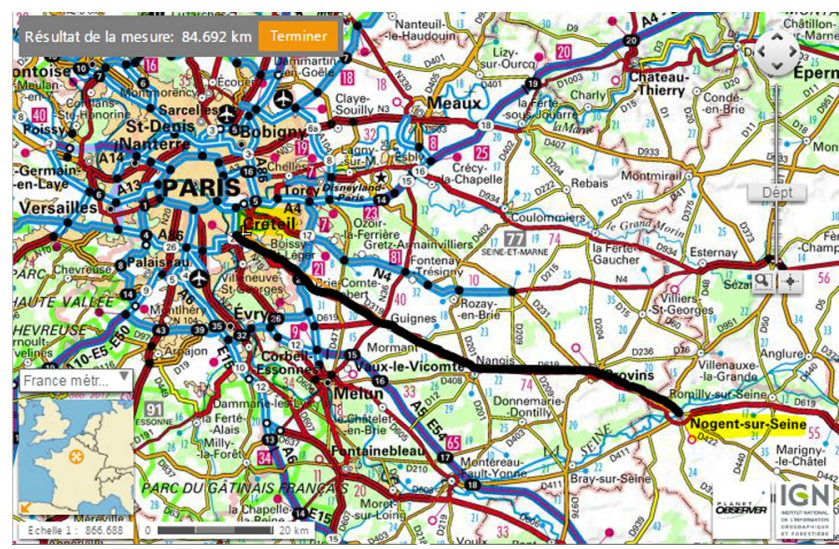

Fig. 5. Overview of the Nogent/Paris case [22].

becomes more complex and its installation becomes a far more delicate matter. We have therefore assumed that the last $10 \mathrm{~km}$ section will be routed in a tunnel.

The basic distance of $90 \mathrm{~km}$ remains a purely hypothetical distance; technical and routing constraints may impose a significantly longer route in reality. Two assumptions will therefore be studied, which increase the transport distances by $25 \%$ and $50 \%$, respectively.

In practice, take-off stations will be included on the main pipeline to distribute some of the heat to local networks along the route (Fig. 5).

In 2013, the Paris region consumed 13.6 TWh of heat supplied by installations providing a combined power of $10,000 \mathrm{MW}_{\text {th }}[16]$. The Paris metropolitan area alone consumed $5 \mathrm{TWh}$ supplied by $\mathrm{CPCU}^{4}\left(4000 \mathrm{MW}_{\text {th }}\right.$ installed) [23].

For our initial calculations we used a power supplied by a reactor of $P=1500 \mathrm{MW}_{\text {th }}$ which corresponds to a supply of $4.5 \mathrm{TWh}_{\mathrm{th}}$ for a hypothetical operating period of $3000 \mathrm{~h}$.

This value is a crucial parameter in the computation, but first of all, it is a major political goal in the framework of the French Energy Transition. Such a goal may seem high in relation to current consumption, but it is based on the forecast demand for heat over the next few decades (which is a similar time frame to that of the project in question), which predicts an increase in consumption to $28 \mathrm{TWh}_{\text {th }}$ by 2030 in the Paris region. By then, the share of nuclear cogeneration of $4.5 \mathrm{TWh}_{\text {th }}$ will only represent $15 \%$ of the total energy mix, which appears to be reasonable. Clearly, such an amount of heat implies that a large number of local networks will be linked to the Nogent pipe, in an extended area of the whole Parisian metropolis, not only in the south or south east of Paris.

The power and temperatures of the hot and cold pipes were calculated along with the mass flow rate of water $\left(Q_{v}=7.3 \mathrm{~m}^{3} / \mathrm{s}\right)$. The pipe diameter was then determined by iteration in order to minimise the cost of investment.

\footnotetext{
${ }^{4}$ Compagnie Parisienne de Chauffage Urbain: the Paris district heating company.
} 
Table 1. Input assumptions for Nogent-Paris.

\begin{tabular}{|c|c|c|}
\hline & \multicolumn{2}{|c|}{ Scenarios } \\
\hline & Low & High \\
\hline Discount rate & $5 \%$ & $3 \%$ \\
\hline Electricity selling price & $70 € / \mathrm{MWh}_{\mathrm{e}}$ & $60 € / \mathrm{MWh}_{\mathrm{e}}$ \\
\hline Heat selling price ${ }^{\mathrm{a}}$ & $39 € / \mathrm{MWh}_{\mathrm{th}}$ & $54 € / \mathrm{MWh}_{\mathrm{th}}$ \\
\hline Technical lifetime & \multicolumn{2}{|c|}{$20 \mathrm{y}$} \\
\hline 3rd loop modifications & \multicolumn{2}{|c|}{$200 \mathrm{M} €[24]$} \\
\hline MTL costs ${ }^{\mathrm{b}}$ & \multicolumn{2}{|c|}{$9.5 \mathrm{M} € / \mathrm{km}$} \\
\hline MTL length & $135 \mathrm{~km}$ & $115 \mathrm{~km}$ \\
\hline
\end{tabular}

${ }^{a}$ Price at the entrance of the distribution network.

b Average cost including the trenches, tunnels, pipes and pumps along the MTL.

Table 2. Economic appraisal for Nogent-Paris.

\begin{tabular}{lcc}
\hline & \multicolumn{2}{c}{ Scenarios } \\
\cline { 2 - 3 } & Low & High \\
\hline$I_{0}$ (overnight) & $1.5 \mathrm{G} €$ & $1.3 \mathrm{G} €$ \\
Incl. MTL & $1.3 \mathrm{G} €$ & $1.1 \mathrm{G} €$ \\
Incl. NPP modif. & \multicolumn{2}{c}{$0.2 \mathrm{G} €$} \\
Cash-flow & $+250 \mathrm{M} € / \mathrm{y}$ & $+300 \mathrm{M} € / \mathrm{y}$ \\
Incl. elec. losses & $-59 \mathrm{M} € / \mathrm{y}$ & $-50 \mathrm{M} € / \mathrm{y}$ \\
Incl. heat sales & $+160 \mathrm{M} € / \mathrm{y}$ & $+220 \mathrm{M} € / \mathrm{y}$ \\
NPV & $-0.92 \mathrm{G} €$ & $0.69 \mathrm{G} €$ \\
POT & - & $13 \mathrm{y}$ \\
LCOH & $56.0 € / \mathrm{MWh}_{\text {th }}$ & $42.0 € / \mathrm{MWh}_{\text {th }}$ \\
\hline
\end{tabular}

For a diameter $\oslash=1600 \mathrm{~mm}$, energy losses are limited to $0.7 \mathrm{bar} / \mathrm{km}$, which imposes the need for $2 \times 7$ pumps along the length of the pipelines to give a total of $60 \mathrm{MW}_{\mathrm{e}}$.

The thickness of the insulation (polyurethane) is also derived from an iterative calculation aimed at optimising thermal losses in relation to the cost of construction. This gives a thickness of $T h k_{\mathrm{PUR}}=7 \mathrm{~cm}$. Contrary to expectation, this value does not depend on the diameter calculated earlier, but only on the economic parameters applied (competition between the heat selling price and the cost of insulation).

Table 1 summarises the main assumptions and aligns them with 2 study scenarios. The first "Low" scenario combines unfavourable parameters in the economic calculation for cogeneration. The second "High" scenario is by contrast more optimistic as it applies the opposing assumptions. Both these scenarios are deemed to be the extreme limits of the actual project model.

\subsection{Economic appraisal: results}

Table 2 shows the main results given by the two abovementioned scenarios.

As could be expected, the two analysed scenarios show two opposite "states of the world". The "low" scenario discourages the use of cogeneration, but in the

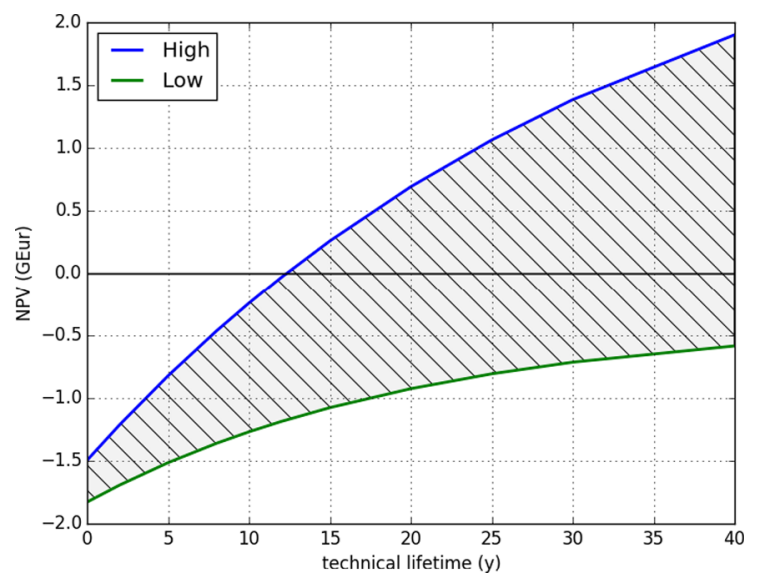

Fig. 6. NPV depending on the technical lifetime of the project.

"high" scenario, the heat produced by the nuclear reactor seems to be competitive against the current production plants.

To explore the temporal aspect of the economy of the project, Figure 6 shows the variation in the NPV for both scenarios on a greater period than the retained technical lifetime.

It shows that the irrelevance of the "low" scenario is not imposed by higher costs during the building phase (leading to an investment of $+33 \%$ after discounting), but the good cash-flows despite more restrictive prices of electricity vs. heat cannot compensate this investment over time because of a discount rate that is still too high. This aspect would reinforce the need for a strong governmental policy to encourage such highly capitalistic projects.

The period of supply of heat is also linked to reactor operation. For Nogent, the act governing operation of $1300 \mathrm{MWe}$ reactors stipulates a time scale of 40 years, which is equivalent to decommissioning in 2027 and 2028. The studies and work needed before heat production can start could last up to 10 years, meaning that cogeneration at this site could only be considered if the operating life of the reactors is extended. This point poses a real difficulty for the project, since ASN, the French nuclear safety authority, is not prepared to guarantee such an extension into the longer term. We therefore need to find ways of mitigating this risk for the operator so that projects like this can go ahead. This could be possible via a guarantee from the government (who would therefore assume the role of insurer) but this supposes a strong political will.

In addition to the integral parameters analysed above, the breakdown of the different cost items based on discounted average cost is presented in Figure 7.

For this project, the main cost is related to building the transportation line. This can be related to the preceding paragraphs, as this vast investment is only interesting in the long run.

For the Nogent plant, it may also be pertinent to look at the opportunity of deploying a new pair of reactors on the site as part of a fleet renewal programme. In this case, it may still be possible to continue to write off the bulk of the investment in the heat distribution network, even if the operating period for these reactors should not exceed 

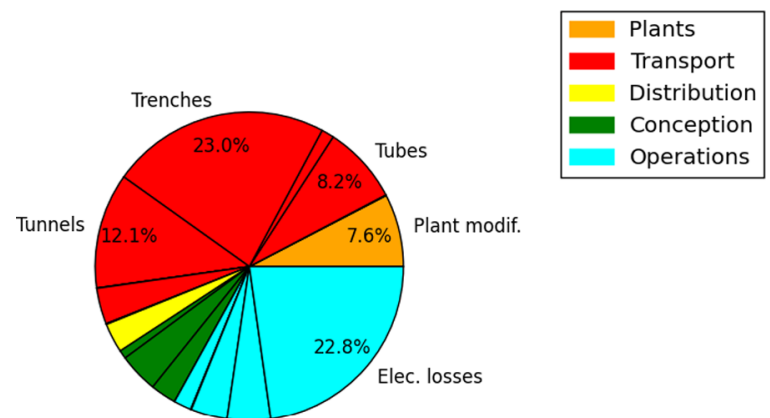

Fig. 7. Structure of the LCOH for Nogent-Paris ("low" scenario).

40 years. From the perspective of the first half of this century, we would be replicating the development model for the Parisian district heating network, the construction of which was initiated during the first half of the previous century, and which has since undergone maintenance as the production methods have gradually been replaced by more efficient facilities.

Finally, the environmental impact of cogeneration between Nogent and Paris mainly relies on the carbon emissions savings. As the DH of the Parisian urban area produced $3 \mathrm{Mt}$ of $\mathrm{CO}_{2}$ (with two thirds from gas) in 2013 [7], say $0.22 \mathrm{t} / \mathrm{MWh}_{\mathrm{th}}$, providing $4.5 \mathrm{TWh}_{\text {th }}$ by nuclear cogeneration in 2030 could save up to $1 \mathrm{Mt}$ of carbon dioxide per year.

\section{Other French sites}

\subsection{Current situation}

Having examined the case of the Nogent-sur-Seine reactors, it makes sense to broaden the scope to examine the other sites which offer the greatest benefit in terms of nuclear cogeneration for DH.

More precisely, we need to focus initially on regions with the highest consumption of DH. Excluding Île-de-France, this corresponds to Rhône-Alpes $\left(2.9 \mathrm{TWh}_{\mathrm{th}}\right)$, Nord-Pas-deCalais $\left(1.1 \mathrm{TWh}_{\mathrm{th}}\right)$, Lorraine $\left(0.9 \mathrm{TWh}_{\mathrm{th}}\right)$, Alsace and Centre $\left(0.75 \mathrm{TWh}_{\mathrm{th}}\right)$ based on 2013 data, see Figure 8.

Figure 9 shows the location of NPPs in France. The red circle around each maps out a $100 \mathrm{~km}$ radius. They are relatively evenly distributed across the country which means that the use of cogeneration could be envisaged for the majority of major conurbations. Among the main areas identified as having a high consumption of $\mathrm{DH}$, only Bourgogne and Franche-Comté (accounting for $1 \mathrm{TWh}_{\text {th }}$ between them) are not particularly well served.

To assess the economic potential of cogeneration, a study of the networks in these regions has been undertaken, and the main consumer sites (coupled with their "reasonable" power $P$ that could be supplied by cogeneration) have been linked to the closest NPP (parameter $D$ ).

For each site studied, we then perform a calculation derived from that presented in detail for Nogent-Paris.

For these sites generating less power, the costs of modifying the tertiary circuit must be adapted. These costs, including the safety report, immobilisation of the

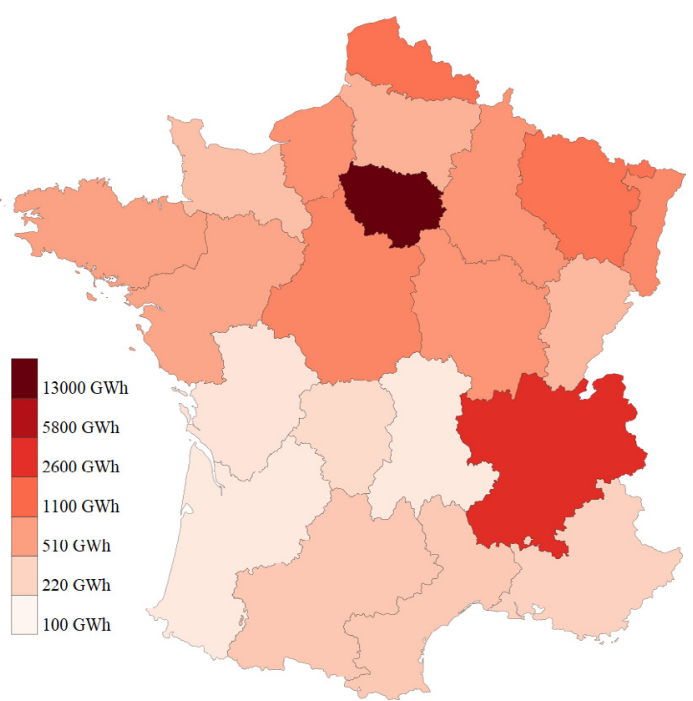

Fig. 8. Heat provided via DH in 2013 in France (personal work from [7] data).

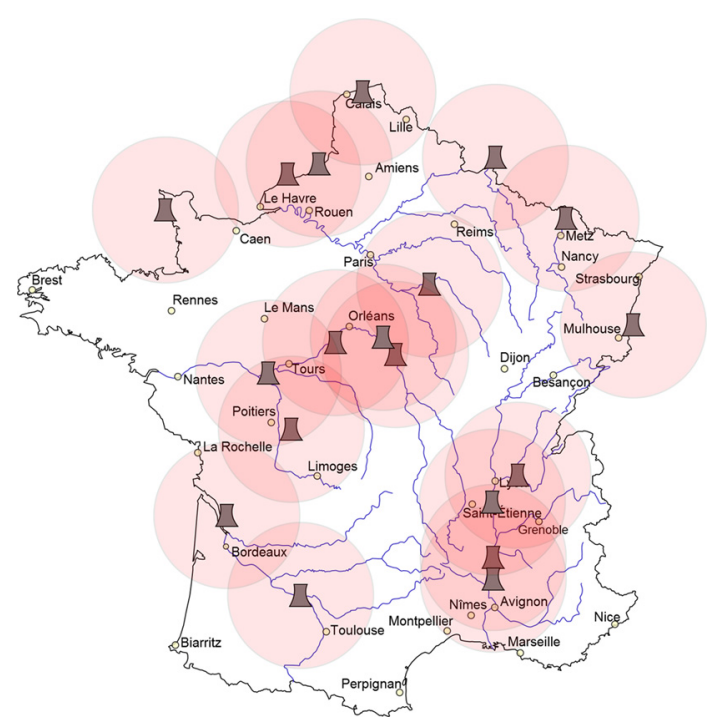

Fig. 9. Location of French nuclear reactors (personal work).

plant and the technical modifications, correspond in an initial approximation to a fixed component (€50 million) and a variable component that depends on the extracted power $\left(€ 0.1\right.$ million $\left./ \mathrm{MW}_{\text {th }} \times \mathrm{P}\right)$.

However, this does not take account of the fact that part of the research and safety assessment costs can be shared across several cogeneration sites.

The procedure for identifying pipe dimensions is also simplified, and in all projects outside the Paris area research suggests that it is possible to avoid having to resort to tunnels. ${ }^{5}$

\footnotetext{
${ }^{5}$ For Grenoble and Chambéry, which have large district heating networks, the use of tunnels to link Bugey, St Alban or Cruas will significantly reduce the transport distance but the associated additional cost is prohibitive in comparison with trenches.
} 


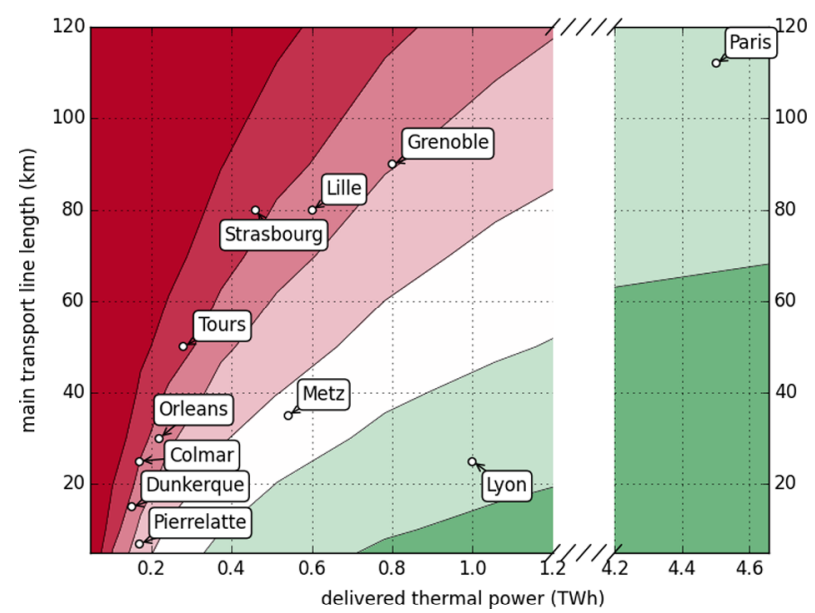

Fig. 10. Economic assessment of French sites (high scenario).

Ultimately, this study is more prospective and only seeks in the first instance to provide food for thought which will help prioritise sites to ensure we focus on those offering the greatest economic interest.

\subsection{Results}

Figure 10 presents a relative comparison of the $\mathrm{LCOH}$ evaluated for the most interesting sites studied. The curves illustrate the competitive areas in relation to the current price of heat.

The Lyon-Bugey project stands out clearly, as it presents a final LCOH less than that of Paris-Nogent ${ }^{6}$ resulting in a considerably lower transport distance and deliverable thermal power $\left(300 \mathrm{MW}_{\mathrm{th}}\right)$. It therefore appears to be the best candidate for deploying nuclear cogeneration.

It is also apparent that the distance parameter is not the only factor determining project viability. The alignment between the distance and the power supplied also plays a major role. The potential to use cogeneration for Metz $(35 \mathrm{~km}$ from Cattenom) is therefore greater than that of Dunkerque (15 km from Gravelines): for Metz the actual heat consumption is compatible with the cogeneration facility, whereas consumption would have to be doubled to reach an economically viable level for the Dunkerque project.

This suggests that long distances still present an obstacle to the development of cogeneration as they require highly developed networks to become profitable.

Like the research carried out by the Île-de-France DRIEE ${ }^{7}$ specific studies can assess the potential for developing networks in these towns. If we consider that, like for the Paris area, it is possible to envisage a doubling of heat consumption between now and 2030, a good number of

\footnotetext{
${ }^{6}$ It might even be possible to consider linking Lyon and St Alban (1300 MW PWRs commissioned almost 10 years after the $900 \mathrm{MW}$ PWRs at Bugey); when $D=45 \mathrm{~km}$ cost remains competitive.

${ }^{7}$ Direction Régionale et Interdépartementale de l'Environnement et de l'Energie (regional and interdepartmental directorate for energy and the environment).
}

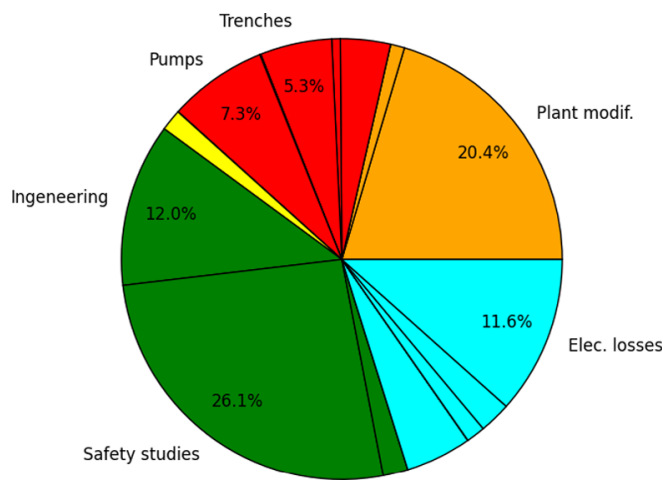

Fig. 11. LCOH structure for Pierrelatte $\left(7 \mathrm{~km}, 170 \mathrm{GWh}_{\mathrm{th}}\right)$.

towns shown in Figure 10 may reach the necessary level of potential to ensure viability. ${ }^{8}$ Additionally, an extension of our work will be able to take account of the need for industrial heat, which may, in certain areas in France, exceed the local demand for heating in the domestic and commercial sectors.

It is also clear that the energy potential for the technology under consideration is in the order of several additional TWh (compared with Paris). To reach a target such as that put forward by the ANCRE scenario, these networks need to undergo significant development, which could, in return, offer the advantage of lowering "nuclear" heating costs.

Whichever scenario is applied, a first rough estimate of the amount of (overnight) investment in heat distribution systems for these projects would be in the order of $€ 60$ million (Pierrelatte, Dunkerque) to $€ 400$ million (Grenoble). For the two stand-out projects-Lyon and Metz - it would be around $€ 150$ million.

The cost structure for projects involving long transport distances (Strasbourg, Lille, Grenoble) is very similar to that illustrated for Nogent (see Fig. 7). By contrast, the situation for Pierrelatte and Dunkerque located close to the NPPs is very different, as shown in Figure 11.

For short distances, the "Design" share of the costs is much greater and ultimately plant modifications and administrative and regulatory expenses are by far the largest components despite a low thermal power extraction requirement $\left(50 \mathrm{MW}_{\text {th }}\right)$. Once again, in the case of deploying cogeneration on several sites, part of these costs could be shared, which leaves room for not insignificant economies of scale.

Depending on the project analysed, it is not the same items which need to be determined.

\section{Conclusions}

DH by nuclear cogeneration is currently used in some countries in Northern and Eastern Europe. The current push by some countries for an Energy Transition Act, as well as the progress made in long distance heat transpor-

${ }^{8}$ For Grenoble, though, the network must already be close to its maximum development potential. 
tation techniques, has brought about the re-evaluation of nuclear cogeneration in France. This paper provides an initial appraisal of this new context. These preliminary results, even if they are still only partial and require confirmation by comprehensive specific case analyses (Nogent-sur-Seine in particular), offer hope for significant development of this promising technology, not only in the Paris area, but in the rest of the country as well.

However, even if there is great national potential in theory, this technology has yet to be validated on the scales envisaged here, in particular for existing reactors, which are the subject of this study. At least two specific questions relate to such reactors. The first concerns the long-term sustainability of centralised electricity production sites (which impacts the capability to generate heat over time), which in turn depends on the combination of the remaining operational life of the existing reactors and the visibility of future investment in the sites themselves or in the local area. The second is the question of scheduling the work needed to modify the standard reactor design, which would involve new regulations (governing heat production), is costly and may be accompanied by a loss of production while work is carried out.

These questions should be addressed on a case-by-case basis, in much more detail than we cover in this paper within the national context. In addition to the parameters of power and heating distance, which are the basis of our analysis in this paper, each project is in fact specific and has its own different critical parameters. The risks to the investor are therefore not the same. The amount of investment required in all cases is in the order of hundreds of millions of euros. Funding is therefore an important aspect and should be the subject of specific studies and developments [25].

At national level, the challenge would be to generate a dozen TWh over the next 10-15 years and reach several dozens of TWh by 2050, the deadline specified in the French Energy Transition Act. A positive factor would also be to develop cogeneration for heating in industrial applications (around Dunkerque for example), which could significantly increase the energy produced and therefore profitability.

At this stage our work shows that nuclear cogeneration technology, which could prove sufficiently interesting in the future, will need a strong commitment from the government to develop it, so that it provides economic benefit and reduces the risks and uncertainties associated with investing such large sums.

Future studies could focus first on a careful assessment of the main promising sites, where nuclear cogeneration appears possibly valuable. Hypothesis must be established with more robustness, in particular those related to the potential market size, in a medium run dynamics. Other points must by consolidated, such as assessing the cost of a back-up system, taking account of development opportunities for existing or planned heating networks, or a better characterisation of the costs of certain decisive elements in the analysis (pipes and installation of the pipeline, modification of the plant, etc.). It is now necessary to conduct further studies which target very specific cases on the one hand, and the wider national context on the other, by evaluating on a national scale the measures required to overcome the inherent obstacles to this technology, such as the actions being taken currently for other "low carbon" energies under the Energy Transition Act draft in force in France.

\section{Nomenclature}

$\begin{array}{ll}\text { CHP } & \text { combined heat power } \\ \text { DH } & \text { district heating } \\ \text { LCOH } & \text { levelised cost of heat }\left(€ / \mathrm{MWh}_{\mathrm{th}}\right) \\ \text { LTECV } & \begin{array}{l}\text { French Energy Transition Act "The Energy Transi- } \\ \text { tion for the Green Growth" }(\text { Loi relative à la }\end{array} \\ & \begin{array}{l}\text { Transition Energétique pour la Croissance Verte) } \\ \text { main transport line }\end{array} \\ \text { NPP } & \text { nuclear power plant } \\ \text { NPV } & \text { net present value }\left(\text { expressed in } \mathrm{M} €=10^{6} €\right) \\ \text { POT } & \text { pay-out time } \\ \text { PUR } & \text { polyurethane } \\ \text { PWR } & \text { pressurised water reactor } \\ P & \text { thermal power }\left(\mathrm{MW}_{\text {th }}\right) \text { of the studied project } \\ D & \text { distance }(\mathrm{km}) \text { between the NPP and the town }\end{array}$

\section{References}

1. http://www.cop21.gouv.fr/

2. http://www.developpement-durable.gouv.fr/-Francelaunches-its-energy

3. ANCRE, Scénarios de l'ANCRE pour la transition énergétique, Agence Nationale de Coordination de la Recherche sur l'Energie, Rapport, 2013

4. I. Khamis, Prospects for nuclear cogeneration, economic assessment methodologies and tools, in Joint NEA/IAEA Expert Workshop on the Technical and Economic Assessment of Non-Electric Applications of Nuclear Energy (NUCOGEN) (2013)

5. D.S. Scott, Exergy, Int. J. Hydrogen Energy 28, 369 (2003)

6. ADEME, Catalogue Climat, Air et Energie, 2014

7. DRIEE, Evaluation du potentiel de développement du chauffage urbain en Île-de-France, October 2012

8. La gestion de la délégation de service public du chauffage parisien, Rapport d'observations définitives, Ville de Paris (75), Chambre régionale des comptes d'Ile-de-France, 10-UC0220/S3/2080226/MC, 2008

9. Geschäftsbericht vom 1. Juli 2003 bis 30. Juni 2004, REFUNA AG (Regionale Fernwärme Unteres Aaretal)

10. H. Safa, Heat recovery from nuclear power plants, Electr. Power Energy Syst. 42, 553 (2012)

11. B. Lerouge, Presentation of a calorigenic swimming-pool reactor and study of its use for urban heating, desalination of water, and other industrial applications, in Study group of the use of the heat of reactor by industry and for urban heating, Vienna, Austria, 2-6 September 1974, ORNL-TR-4259 (1974)

12. Non-Electric Applications of Nuclear Power: Seawater Desalination, Hydrogen Production and other Industrial Applications, in Proceedings of an International Conference, Oarai, Japan, 16-19 April, 2007, IAEA-CN-152 (2007)

13. Baromètre IRSN, La perception des risques et de la sécurité par les français, IRSN, 2014 
14. H. Tuomisto, CHP Study for Loviisa Unit 3 in Finland, private communication at CEA, 01/31/12

15. EuroHeat \& Power, District Heating and Cooling Country by Country Survey, 2013

16. FEDENE (Fédération des services énergie environnement), SNCU (Syndicat National du chauffage urbain et de la climatisation urbaine), Enquête nationale sur les réseaux de chaleur et de froid, Rapport, 2014

17. OCDE, Nuclear Power Plant Life Management and Longerterm Operation, NEA n6105, 2006

18. R. Narjot, Réseaux de chaleur, Les Techniques de l'Ingénieur, B 2170 (1985)
19. Commission de Régulation de l'Energie: www.cre.fr

20. Prix moyen de la chaleur vendue par réseau, Base de données CARMEN, DRIEE Ile-de-France

21. Elecnuc-Les centrales nucléaires dans le monde, Edition 2014, CEA/I-tésé: www.cea.fr

22. IGN: www.geoportail.gouv.fr

23. CPCU: www.cpcu.fr

24. K. Verfondern, private communication (2011)

25. L. Martin, Pas de croissance soutenable sans innovations financières - La cogénération nucléaire, projet d'importance stratégique pour la transition écologique, Entreprendre et Innover, 25 (2015)

Cite this article as: Frédéric Jasserand, Jean-Guy Devezeaux de Lavergne, Initial economic appraisal of nuclear district heating in France, EPJ Nuclear Sci. Technol. 2, 39 (2016) 